Article

\title{
Analysis on the Coupling Relationship and Coordinated Development between the Construction of Ethnic Minority Tourist Towns and the Tourism Industry
}

\author{
Ling Lin and Jiangfeng $\mathrm{Li}^{*}$ \\ School of Public Administration, China University of Geoscience, No. 388 Lumo Road, Wuhan 430074, China; \\ linling010@126.com \\ * Correspondence: jfli0524@163.com
}

Citation: Lin, L.; Li, J. Analysis on the Coupling Relationship and

Coordinated Development between the Construction of Ethnic Minority Tourist Towns and the Tourism Industry. Sustainability 2021, 13, 2451 https://doi.org/10.3390/su13052451

Academic Editor:

Juan Ignacio Pulido-Fernández

Received: 19 December 2020

Accepted: 21 February 2021

Published: 24 February 2021

Publisher's Note: MDPI stays neutral with regard to jurisdictional claims in published maps and institutional affiliations.

Copyright: (C) 2021 by the authors. Licensee MDPI, Basel, Switzerland. This article is an open access article distributed under the terms and conditions of the Creative Commons Attribution (CC BY) license (https:// creativecommons.org/licenses/by/ $4.0 /)$.
Abstract: The construction of minority characteristic tourist towns and the coordinated development of the tourism industry is an important way for ethnic minority tourist towns to improve their economic, social, resource, and environmental development levels. This article analyzed the mechanism of the coupling and coordination relationship between the construction system of ethnic minority characteristic tourist towns and the tourism industry system from three aspects: economy, society, and resource environment. Taking Longi Town as the research object, we constructed an index system for the coupling and coordinated development of the two systems. By using the coupling coordination degree model to analyze the coordinated development of Longji Town construction and tourism industry from 2013 to 2018, we found that the two systems generally show an upward development trend, and the degree of coupling coordination has changed from barely coupling coordination to good coupling coordination. The construction level of Longji Town and the degree of coupling coordination of the tourism industry system were manifested as the lagging development of the town construction level and the lagging tourism industry development alternately. The leading role of the development of Longii's tourism industry in the construction of small towns was fluctuating and lacked stability. According to the research results, a policy reference for the sustainable development path of minority characteristic tourist towns was proposed.

Keywords: small-town construction; tourism industry; coupling; Longji Town

\section{Introduction}

The increase in people's recreational demand and tourism consumption has promoted the development of tourism activities and the development of tourism. The development of tourism drives the agglomeration and diffusion of population, capital, and material to the tourism-reliant areas [1], drives regional development [2,3], as well as the promotion of urban functions and the formation of local tourist towns [4]. Tourist towns refer to small towns that combine tourism development and small-town construction [5]. Its connotation is a relatively independent development in space and a regional complex dominated by the tourism industry. Tourist towns can be either institutional towns or market towns, tourist real estate projects, or historical and cultural villages [6]. Small tourist towns have developed rapidly since the 1870s. With the decline of traditional industries such as agriculture, mining, and forestry, tourism has become an important driving force for the economic development of many small towns [7,8]. The development of tourism in small towns can enrich and improve the industrial structure, promote employment, increase residents' income, promote infrastructure construction, and promote local culture [9]. For regions with rich tourism resources, tourism is not only a sustainable livelihood choice for cities and towns, but the development of cities and towns also supports the development of tourism $[10,11]$. Therefore, the development of tourist towns is not only a life cycle process of tourism industry development, but also a choice to realize the integrated development of 
urban and rural areas. At the same time, the coordinated development of the tourist town construction system and the tourist industry system is the path choice for the sustainable development of tourist towns [12].

The interaction between the development of small towns and the tourism industry has attracted widespread attention from domestic and foreign scholars. In the mid-1970s, the role of tourism in the development of cities and towns became increasingly obvious, and cities and towns became the supporting points of modern tourism. Haw and Williams directly pointed out that cities have a very important position in the tourism industry [5]. In 1991, Mullins first clearly put forward the concept of "tourism urbanization" and pointed out that the coordinated development of tourism and urban construction is not only a place to create consumption, but also to improve consumer satisfaction [1]. Subsequently, international studies on the relationship between urban construction and tourism have been deepened. First, the relationship between urban development and the tourism industry. The development of tourism has a significant positive impact on urban construction $[1,13]$. Urban construction has a direct or indirect effect on the development of tourism economy [14]. Yang and Grah believed that there is an interactive relationship between tourism and urban development $[10,15]$. Xi believed that tourism development can induce changes in the spatial layout of residential areas [16]. Second, the coordinated development of urban unilateral factors such as tourism and ecological environment, culture, and transportation in medium and large cities [17]. Third, the coordinated development of tourism and urban construction in large cities or urban agglomerations [12,18,19]. Fourth, the authenticity of tourist town culture has an impact on tourism development $[20,21]$. The more complete the heritage of cultural authenticity, the more attractive the tourist town can be. Fifth, the sustainable development of tourist towns. The current research directions mainly include sustainable ecological environment, sustainable living environment, sustainable livelihood, and cultural sustainability [22-24]. Research showed that the theory of sustainable tourism is crucial to the sustainable development of tourist towns.

In summary, research on the relationship between urban construction and the tourism industry is increasing. The research perspective focuses on the relationship between the development of the tourism industry and urban construction or urban society, economy, and culture. The previous research has laid the foundation for the deepening of this article. In the past, the research mainly tended to large cities, urban agglomerations, and national scales with mature tourism development, while small and medium cities are the basic unit of interaction between tourism economy and its construction. Based on the scale of small- and medium-sized cities, it is of great significance to study the coordination effect of small-town construction and the tourism industry and their evolution characteristics. Compared with the past, this article investigated the existing status of cultural resources in ethnic minority characteristic tourist towns through questionnaires, and it is more targeted to analyze the comprehensive development level of minority characteristic tourist towns.

With the implementation of China's urban-rural integration development policy, China's ethnic minority settlements rely on abundant tourism resources to actively promote the development of tourist towns. The development of ethnic minority tourism resources not only promotes the improvement of the economic development level of small towns and the improvement of the social security system, but also realizes the protective development of ethnic culture. At the same time, minority characteristic tourist towns are also facing practical problems such as the assimilation of minority cultures by foreign cultures [25] and the decline of environmental quality [26]. Therefore, by exploring the coupling and coordination mechanism and coupling relationship between the construction of minority characteristic tourist towns and the development of tourism industry, it is of practical significance to solve the problems facing the development of minority characteristic tourist towns and realize the sustainable development of minority characteristic tourist towns.

Based on the existing research results, we analyzed the coupling relationship between the construction of minority characteristic tourist towns and the tourism industry in Section 2. On this basis, an evaluation index system for the coordinated development 
of the two was constructed to show the characteristics of the coordinated development of town construction and tourism. There are three reasons why we take Longi Town as the case site. First, Longji Town is a small town inhabited by multiple ethnic groups. The main ethnic groups are Zhuang, Yao, Han, and other ethnic groups. The minority population of Longji Town accounts for more than $80 \%$ of the total population of the town. Longji Town is rich in cultural resources of ethnic minorities. However, influenced by foreign cultures, ethnic minority cultures are facing a crisis of assimilation [27]. Second, from 2013 to 2018, the proportion of tourism in Longji Township accounted for more than $30 \%$ of GDP. Therefore, the economic development of Longji Town is based on tourism as its pillar industry. It belongs to a typical minority cultural tourist town. Third, Longji Town is located in the Guilin tourism circle, which not only supports the development of Guilin's tourism industry, but also benefits from Guilin's international influence. Taking Longji Town as a case study, this article has three main research purposes, including analyzing the comprehensive development level of minority characteristic tourist towns, the coordination relationship between the construction of minority characteristic tourist towns and the tourism industry, and the temporal and spatial evolution characteristics of this relationship. Therefore, we first established an evaluation index system for the coordinated development of the construction of ethnic minority tourist towns and the tourism industry and, then, constructed the coupling and coordination model of the two subsystems. Finally, the temporal and spatial evolution analysis of the coordination relationship between the two systems of Longji Town was carried out.

\section{An Analysis of the Mechanism of the Coupling and Coordination Relationship between the Construction of Ethnic Minority Tourist Towns and the Tourism Industry System}

In physics, coupling refers to the phenomenon that two (or more than two) systems or forms affect each other through various interactions. When the systems or the internal elements of the system cooperate properly and promote each other, it is a benign coupling. On the contrary, it is a poor coupling. Coupling degree describes the degree of interaction and influence of systems or elements. Coordination is a benign interrelationship between two or more systems or system elements [28]. It is a relationship between systems or elements within a system that is properly coordinated, harmonious, and virtuous. It is a guarantee for the healthy development of multiple systems or elements. Coupling coordination degree is a measure of the degree of harmony between systems or between internal elements of the system in the development process and reflects the trend of the system from disorder to order [29]. There is a difference between the degree of coupling and the degree of coupling coordination. The degree of coupling mainly reflects the strength of the interaction between systems, regardless of pros and cons. Coupling coordination degree indicates the degree of benign coupling in the interaction and reflects the degree of coordination.

Ethnic minority characteristic tourist towns are a composite system composed of economy, society, resources, and environment [6]. Tourism is not only an economic phenomenon, but also a social and cultural phenomenon with high demands on the ecological environment $[30,31]$. From this perspective, the development of the tourism industry and the construction of small towns are at the same level of mutual influence and coordination between economy and economy, society and society, resource environment and resource environment, similar to the abovementioned coupling and coordination phenomenon $[17,32,33]$. This article refers to economic coupling coordination, social coupling coordination, resource environment coupling coordination [34]. The following explains the interaction mechanism between the development of tourism industry and the construction of minority characteristic tourist towns from these three aspects.

\subsection{Economic Coupling Coordination}

The economic effects of the development of the tourism industry on small towns are mainly reflected in the improvement of the economic development level of small towns, the 
promotion of industrial structure upgrading, and the living standards of small-town residents, thereby forming a unique cultural economy $[35,36]$. First, the tourism industry has the characteristics of strong comprehensiveness, high relevance, obvious multiplier effect, broad industrial base, wide employment coverage, and large investment. It can not only enhance the economic strength of small towns, but also drive related industries in small towns. The development of tourism, for example, can directly promote the development of urban catering, accommodation, transportation, commerce, and entertainment industries and indirectly promote the development of investment, construction, and education and cultural industries. Second, it can promote the upgrading of the industrial structure of small towns. Through the integration of tourism industry clusters, the development of the tourism industry and the primary, secondary, and tertiary industries will be realized, resulting in "dual benefits", and achieving industrial quality and efficiency. Tourism development drives the development of related service industries, gradually increases the proportion of the tertiary industry in cities and towns, and promotes the advanced and rationalization of the industrial structure of small towns.

The construction of small towns gathers numerous development elements and provides complete facilities for the development of the tourism industry [37,38]. Small towns have completed micro-aggregation subjects and a unified factor market. Therefore, the agglomeration of the tourism industry in small towns has comparative advantages and competitive advantages. Besides, small towns have the functions of tourism management, reception, distribution, and radiation centers and provide facilities and services in entertainment, culture, commerce, finance, industry, production services, transportation transit, official affairs, and government affairs, which are the foundation for the healthy development of the tourism industry.

\subsection{Social Coupling Coordination}

Tourism is an all-round social activity that promotes social progress in terms of increasing employment opportunities in small towns, improving the quality of residents, and ensuring residents' living standards $[39,40]$. First, the tourism industry has laborintensive advantages and can provide many local employment opportunities for smalltown residents, thereby increasing the income of the employed population and social security. Second, a variety of tourism product facilities can meet the livelihood needs of small-town residents to relax and pursue health. At the same time, tourism can realize direct and indirect communication between urban residents and foreign tourists and enhance mutual understanding, communication, and development between people [41]. Third, the residents promote the transformation of urban residents' concepts, ideology, behavior, hygiene habits, business awareness, and lifestyles by imitating and learning from tourists. The construction of small towns promotes the development of the tourism industry [42]. Small towns have more employment opportunities and better medical and health care, education and learning, and other guarantee conditions, which can attract more labor resources, knowledge, and culture gathering and produce social effects.

\subsection{Resource and Environment Coordination}

For cultural resources, the tourism industry promotes the utilization and protection of cultural resources in tourist towns [43-45]. It makes people realize that cultural resources can be transformed into economic wealth, prompting people to actively explore, organize, protect, construct, innovate, and develop national culture [46,47]. The popularization of residents' knowledge of science, culture, history, etc., becomes improved as well as their scientific and cultural literacy and their awareness of protecting national culture. Tourism image transforms the intangible resources of small towns into tourist attractions, tourism experience products, and tourism consumer goods and realizes the visual communication of small-town culture [48]. The history, folk customs, landscape, industry, art, fashion, and other cultural tourism resources of ethnic minorities are the foundation and "soul" of enriching ethnic tourism products. Ethnic minority culture is the core resource for the 
development of local tourism. Its degree of protection of "authenticity" will not only affect the attractiveness of tourism products, but also affects the establishment of local tourism image [49].

For the ecological environment, the beautification of small towns and the restoration and reconstruction of the ecosystem are benefited by tourism development [33]. Compared with other traditional industries, the tourism industry is called "smoke-free industry", which has the characteristics of resource saving and environmental friendliness and has a relatively small impact on the environment. Tourism environment is the foundation of tourism survival. It is a tourism resource. Tourism can lead and force the development of green and ecological industries in small towns. At the same time, in order to increase the attractiveness of tourists, small towns need to protect and beautify the ecological environment. Through the development of low-consumption and intensive tourism projects, tourism is closely integrated with agriculture and industry to achieve smart growth. A good ecological environment is the basis for tourism development [32].

\section{Empirical Research}

\subsection{Research Area Overview}

Longji Town is in the northeastern part of Guangxi Zhuang Autonomous Region and belongs to the Longsheng Autonomous County. It is located between $109^{\circ} 32^{\prime}-100^{\circ} 14^{\prime}$ east longitude and $25^{\circ} 35^{\prime}-26^{\circ} 17^{\prime}$ north latitude. Longji Town is rich in natural and cultural tourism resources, with terraced landscapes with a history of more than 650 years, a harmonious natural artificial ecosystem, and unique Zhuang and Yao customs and culture. The Chinese government has taken the opportunity of building a national 5A-level scenic spot "Longji Terraces" as an opportunity to build the "Longji International Tourist Town" with high standards. The main ethnic groups in Longii Town include Zhuang, Yao, Han, and other ethnic groups. It is a tourist town where many ethnic groups live in concentrated communities. Driven by and influenced by Guilin tourism, Longji Town will give full play to the rich resources and distinctive advantages of the Guilin tourism circle to vigorously develop the tourism industry. Today, Longji Town's tourism industry has become an important driving force for the economic development of small towns. From 2013 to 2018, the tourist reception volume of Longji Town showed a rapid growth trend $(0.7,0.8,1.0$, $1.1,1.2,1.5$ million person-times), but the reception volume of cross-border tourists is $0.068,0.080,0.100,0.098,0.082,0.098$ million person-times, affected by the international market, showing a fluctuating development state. Total tourism revenue increased from 0.031 billion in 2013 to 0.060 billion in 2018, which is equivalent to $48 \%$ of GDP that year.

\subsection{Research Method}

\subsubsection{Index System and System Comprehensive Evaluation Model}

From the previous analysis, we can see that there is a phenomenon of coupling and coordination between the construction of small towns and the development of the tourism industry. The development of the tourism industry and the construction of small towns are composed of different development elements. Therefore, it is necessary to quantitatively analyze the coupling degree of the dual system and construct a relevant index system reflecting the development characteristics of the two. The construction of tourist towns and the development of the tourism industry system involve factors such as economy, social culture, and environment. Following the principles of system completeness, feasible operability, comparative comparability, representative typicality, and combination of quantitative and qualitative evaluation index system, this article systematically analyzes the connotation of the evaluation factors and builds an evaluation index system for the construction of minority characteristic tourist towns and the coordinated development of tourism industry (Table 1). The tourism industry coupling coordination system is divided into two systems: the construction of minority characteristic towns and the development of tourism industry. 
Table 1. Weight of evaluation index system of coupling system of tourism small-town construction and tourism industry.

\begin{tabular}{|c|c|c|c|c|c|}
\hline Subsystem & Data Sources of Element & Secondary Index & Unit & Weight & Data Sources \\
\hline \multirow{20}{*}{ Town construction } & \multirow{6}{*}{ Economic factors } & x1. GDP per capita & Thousands of dollars/person & 0.0360 & Statistics \\
\hline & & $\mathrm{x} 2$. The proportion of tertiary industry in GDP & $\%$ & 0.0268 & Statistics \\
\hline & & x3. Per capita output value of primary industry & Thousands of dollars/person & 0.0403 & Statistics \\
\hline & & $\mathrm{x}$. Resident income diversity index & $\%$ & 0.0777 & Statistics \\
\hline & & x5. Common wealth (1-poverty rate) & $\%$ & 0.0438 & Statistics \\
\hline & & x6. Per capita net income of rural residents & Thousands of dollars/person & 0.0320 & Statistics \\
\hline & \multirow{7}{*}{ Social factors } & \multirow{2}{*}{$\begin{array}{l}\text { x7. Living standard of rural residents (1-Engel's coefficient) } \\
\text { x8. Rural residents' settlement coefficient (permanent population } \\
\text { / registered population) }\end{array}$} & $\%$ & 0.0221 & Statistics \\
\hline & & & $\%$ & 0.0337 & Statistics \\
\hline & & x10. Consolidation rate of nine-year compulsory education & $\%$ & 0.0228 & Statistics \\
\hline & & x11. Thousands of people have medical care & Medical care/thousands & 0.0256 & Statistics \\
\hline & & $\mathrm{x} 12$. The number of agricultural and industrial technicians in 1000 people & Mechanics/thousands & 0.0342 & Statistics \\
\hline & & $\mathrm{x} 13$. Thousands of people own operating buses & Vehicles/thousand people & 0.1019 & Statistics \\
\hline & & x14. Number of mobile phones per capita & unit & 0.0437 & Statistics \\
\hline & \multirow{7}{*}{ Resources and Environment } & x15. Social Harmony Index & $\%$ & 0.0258 & Statistics \\
\hline & & x16. Degree of protection of cultural heritage & & 0.0389 & Questionnaire \\
\hline & & $\mathrm{x} 17$. Degree of protection of traditional buildings & & 0.0389 & Questionnaire \\
\hline & & x18. Degree of regionalization of ethnic languages & & 0.0411 & Questionnaire \\
\hline & & x19. Inheritance of religious beliefs & & 0.0352 & Questionnaire \\
\hline & & x22. Inheritance degree of rural social relations & & 0.0598 & Questionnaire \\
\hline & & x23. Forest coverage & & 0.0464 & Statistics \\
\hline \multirow{10}{*}{ Tourism Industry } & \multirow{6}{*}{ Industry scale } & x24. Annual good rate of air quality & & 0.0585 & Statistics \\
\hline & & y1. Growth rate of total tourism revenue & $\%$ & 0.0710 & Statistics \\
\hline & & y2 Growth rate of total tourist arrivals & $\%$ & 0.1565 & Statistics \\
\hline & & y3 The growth rate of domestic tourist arrivals & $\%$ & 0.0512 & Statistics \\
\hline & & y4 Growth rate of cross-border tourism reception & $\%$ & 0.1090 & Statistics \\
\hline & & y5 Baidu search index average & $\%$ & 0.0883 & Statistics \\
\hline & \multirow{4}{*}{ Tourism reception capacity } & y6 Average number of days of tourist stay & Days/person & 0.0765 & Statistics \\
\hline & & y7 Number of travel agencies & & 0.1173 & Statistics \\
\hline & & y8 Number of tourist hotels & & 0.2434 & Statistics \\
\hline & & y9 The number of tourism employees as a proportion of employees & $\%$ & 0.0867 & Statistics \\
\hline
\end{tabular}


It can be seen from the concept and connotation of the tourist town that the development of the tourist town involves industrial development, supporting elements, and cultural foundation. MacCnanell proposed that the search for tourist attraction "authenticity" has become the motivation of tourists to travel [20] and the market demand for the authenticity of ethnic minority culture in the development of ethnic tourism [50]. Seeking opinions from experts and using the high frequency index used by CNKI and SCI databases in recent years on the "minority characteristic tourist town", the indicator system of the construction of ethnic minority characteristic tourist towns mainly includes three primary indicators: economic indicators, social indicators, and resource and environmental indicators $[6,17,19,32,51]$, and there are 24 secondary indicators. A lot of relevant studies on tourism industry evaluation and the index system are relatively mature. The selection of tourism industry system indicators mainly draws on existing research results [52-54], including two primary indicators of industrial scale and tourism reception capacity. Based on actual conditions, 9 secondary indicators that reflect the development of the national tourism industry were selected.

\subsubsection{Establishment of Coordination Measurement Model}

Since the selected index units are not the same, in order to ensure the accuracy of the analysis results, the data obtained are firstly processed for dimensionless quantification, and the method of range standardization is required to be dimensionless processed [55].

$$
\begin{aligned}
& x_{i j}^{\prime}=\left[x_{j}(t)-x_{\text {min }}\right] /\left(x_{\max }-x_{\text {min }}\right)+0.001, \\
& y_{i j}^{\prime}=\left[y_{j}(t)-y_{\min }\right] /\left(y_{\max }-y_{\min }\right)+0.001
\end{aligned}
$$

where $x_{i j}^{\prime}, y_{i j}^{\prime}$ are the index values after the change; $x_{j}(t), y_{j}(t)$ represent the original data of the jth index in year $\mathrm{t} ; x_{\max }$ and $y_{\max }$ are the maximum values of the jth index; $x_{\min }, y_{\min }$ is the minimum value of the jth index. In order to avoid the phenomenon of negative value or zero in the non-dimensional quantization process, 0.001 is added to the formula.

(1) Determine the index weight

The index weight of the article is calculated by the entropy method based on expert consultation [17], and the results are shown in Table 1. Proceed as follows:

$$
\begin{gathered}
S_{i j}=x_{i j}^{\prime} / \sum_{i=1}^{m} x_{i j}^{\prime} \\
h_{j}=-\frac{1}{\ln m} \sum_{i=1}^{m} s_{i j} \ln s_{i j} \\
d_{j}=1-h_{j} \\
w_{j}=d_{j} / \sum_{j=1}^{n} d_{j}
\end{gathered}
$$

among them, $S_{i j}$ is the proportion of the $j$ th index in the $i$-th year, $h_{j}$ is the entropy value of the $j$ th index, $d_{j}$ is the difference coefficient of the $j$ th index, and the last $w_{j}$ is the weight of the $j$ th index.

(2) Establish a comprehensive evaluation function for the construction level of ethnic minority characteristic tourist towns [34]:

$$
F(x)=\sum_{i=1}^{n} w_{i} x_{i j}^{\prime}
$$

where $j$ is the number of tourist town indexes $(j=1,2, \ldots, \mathrm{n})$; $w_{i}$ is the index weight; $x_{i j}^{\prime}$ is the standardized value of the $j$ th index constructed in the tourist town in year $i$, and the larger the result, the better the construction of the tourist town, and vice versa. 
(3) Establish a comprehensive evaluation function for the tourism industry

$$
\mathrm{G}(\mathrm{y})=\sum_{i=1}^{n} w_{i} y_{i j}^{\prime}
$$

where $j$ is the number of tourism industry indicators $(j=1,2, \ldots \mathrm{n})$; $w_{i}$ is the indicator weight; $y_{i j}^{\prime}$ is the standardized value of the $j$-th indicator of the tourism industry in the $i$-th year. The bigger the result, the better the state of the industry, while the worse it is on the contrary.

(4) Establishment of coupling function

Coupling degree is the coordinated process of measuring the internal indicators of the system. This article draws on the expression of two system coupling models corrected by Xiaonan Cong [56]. The formula for measuring tourism town construction and tourism industry coordination degree can be expressed as

$$
C=2\left\{\frac{F(x) \cdot G(y)}{[F(x)+G(y)]^{2}}\right\}^{\frac{1}{2}},
$$

where $C$ is the coordination degree (or the coordination degree coefficient). Coordination degree $C$ can be used as an important indicator of system coupling and can reflect the strength of interaction between systems. However, the degree of coordination cannot reflect the overall efficacy and synergy of the system. The current common method is to use the principle of minimization of dispersion to construct a dispersion model to judge the degree of coordination of the system [57]; the formula is:

$$
D=\sqrt{C \cdot T},
$$

among which: $T=\alpha \cdot \mathrm{F}(\mathrm{x})+\beta \cdot \mathrm{G}(\mathrm{y})$, where $D$ is called the coordinated development degree; $\alpha$ and $\beta$ are undetermined coefficients. Since there is a certain difference in the degree of mutual promotion between the development of small towns and the development of the tourism industry, the construction of small towns is the result of multiple factors including the tourism industry. Therefore, based on the research of relevant literature, $\alpha$ and $\beta$ are assigned to 0.6 and 0.4 , respectively.

In order to directly reflect the coupling degree of the coordinated development of the small-town construction system and the tourism industry system, the degree of coupling and coordination of the two subsystems is classified. The value range of coordinated development degree $D$ is $[0,1]$. Using the median segmentation method, according to the change in $D$ value, the system coordination degree interval can be divided. Coupling coordination degree levels mainly include "four-point method", "six-point method", "seven-point

\begin{tabular}{|c|c|c|c|}
\hline $\begin{array}{l}\text { Accidentally and } \\
\text { Coordination } \\
\text { Degree }\end{array}$ & $\begin{array}{l}\text { Accidentally and } \\
\text { Coordination } \\
\text { Degree Level }\end{array}$ & $\begin{array}{c}\text { Accidentally and } \\
\text { Coordination } \\
\text { Degree }\end{array}$ & $\begin{array}{c}\text { Accidentally and } \\
\text { Coordination } \\
\text { Degree Level }\end{array}$ \\
\hline $0 \sim 0.09$ & $\begin{array}{c}\text { Extreme } \\
\text { maladjustment }\end{array}$ & $0.5 \sim 0.59$ & $\begin{array}{l}\text { Grudging } \\
\text { coordination }\end{array}$ \\
\hline $0.1 \sim 0.19$ & Severe maladjustment & $0.6 \sim 0.69$ & Primary coordination \\
\hline $0.2 \sim 0.29$ & $\begin{array}{c}\text { Moderate } \\
\text { maladjustment }\end{array}$ & $0.7 \sim 0.79$ & $\begin{array}{l}\text { Intermediate } \\
\text { coordination }\end{array}$ \\
\hline $0.3 \sim 0.39$ & Mild maladjustment & $0.8 \sim 0.89$ & Good coordination \\
\hline $0.4 \sim 0.49$ & $\begin{array}{l}\text { On the verge of } \\
\text { maladjustment }\end{array}$ & $0.9 \sim 1.0$ & $\begin{array}{l}\text { High quality } \\
\text { coordination }\end{array}$ \\
\hline
\end{tabular}
method", and "ten-point method" [57]. This article uses the ten-point method (see Table 2).

Table 2. Ranking of coupling and coordinating degree. 


\section{Result Analysis}

\subsection{Data Source}

The data sources of this article include data collection and interview questionnaires. Data types were divided into objective data and subjective data. The objective data came from the "Longsheng Statistical Yearbook" officially published by Longsheng, and the time for data release is generally delayed by 1-2 years. This paper selected 2013 2018 as the sample period of this paper. The subjective data came from the author's field survey data in Longji Town in 2019. According to the indicator system, the author constructed a questionnaire reflecting the authenticity of ethnic cultural heritage, conducted oneon-one in-depth interviews with local residents and managers in Longji, and obtained 30 copies data on the authenticity of national cultural heritage of Longji Town from 2013 to 2018. The objective data were manipulated in two statistical methods. One is to directly use the value of the "Statistical Yearbook", and the other is calculated by formula. The calculation method is shown in Table 1. For the subjective data, the values for each year were averaged. The missing individual data were calculated by trend extrapolation and moving average methods.

According to the coupling coordination degree model, the comprehensive evaluation index $F(x), G(y)$, and the coupling coordination degree of Longji Town construction and tourism industry system from 2013 to 2018 were calculated, and the coupling types were classified based on this, as shown in Table 3 and Figure 1.

Table 3. Coupling degree, coordination degree, and evaluation of Longji town construction and tourism industry.

\begin{tabular}{ccccccc}
\hline Year & $\mathbf{F ( x )}$ & $\mathbf{G}(\mathbf{y})$ & $\mathbf{C}$ & $\mathbf{T}$ & $\mathbf{D}$ & Coupling Coordination Degree \\
\hline 2013 & 0.350 & 0.354 & 0.999 & 0.351 & 0.593 & Grudging coordination \\
2014 & 0.258 & 0.327 & 0.993 & 0.286 & 0.533 & Grudging coordination \\
2015 & 0.336 & 0.527 & 0.975 & 0.413 & 0.634 & Primary coordination \\
2016 & 0.593 & 0.263 & 0.923 & 0.461 & 0.652 & Primary coordination \\
2017 & 0.640 & 0.219 & 0.872 & 0.472 & 0.641 & Primary coordination \\
2018 & 0.736 & 0.741 & 0.999 & 0.738 & 0.859 & Good coordination \\
\hline
\end{tabular}

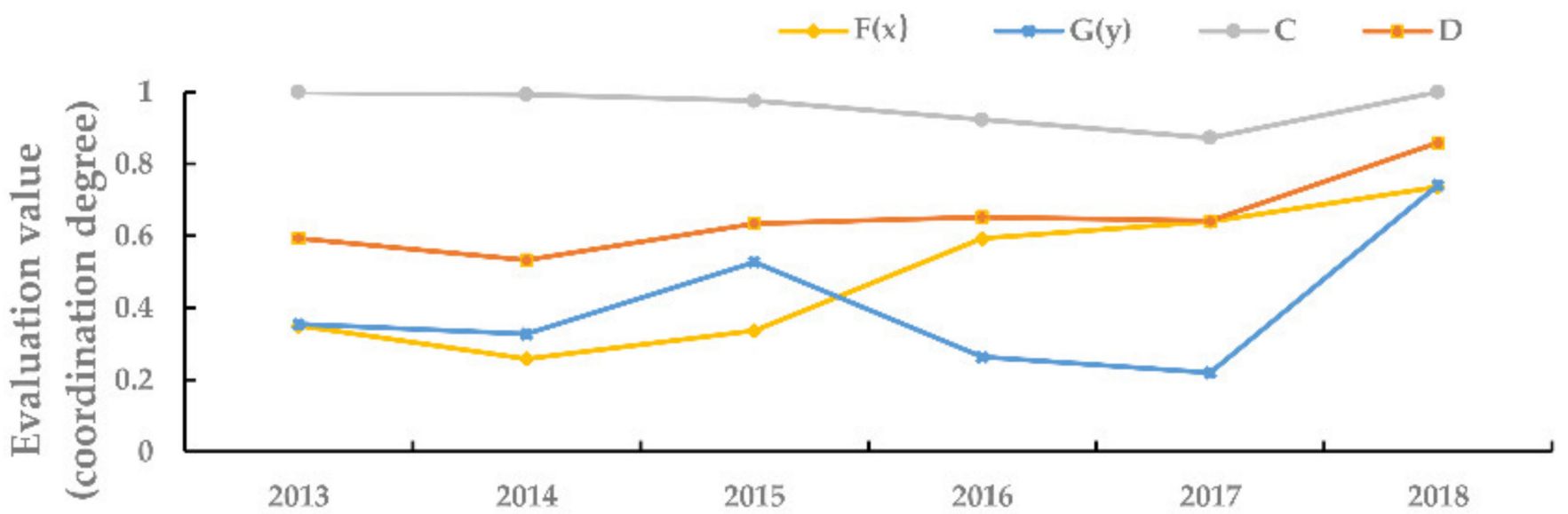

Figure 1. Dynamic evolution curve of coupling index between Longji town construction and tourism industry. 


\subsection{Analysis on the Construction of Ethnic Tourist Towns and the Comprehensive Development} Level of the Tourist Industry

From Table 3 and Figure 1, we can see that from 2013 to 2018, the construction and development level of Longji Town is on the rise, and the development level of Longji Town's tourism industry showed a fluctuating upward trend. From the perspective of the development of the tourism industry system, the growth rate of total tourism revenue in 2014 fell $4.5 \%$ year-on-year, which is the main obstacle to the improvement of tourism development. In 2015, all six indicators of the tourism industry achieved growth, and the development level of the tourism industry increased by $20 \%$ compared with the same period. Compared with 2015, the development level of Longji tourism industry in 2016 and 2017 decreased by 26.4 and 30.8\%, respectively. In 2018, the development level of the tourism industry was the highest, and the comprehensive evaluation function value of the tourism industry reached 0.741 . The reasons were as follows: First, the scarcity or lack of characteristics of tourism products can cause tourists to consume weakly and reduce the level of tourism income in tourist destinations. The occurrence of external environmental crisis events would also delay the occurrence of tourist behavior. Therefore, the number of tourists received in the year decreased, and the development level of tourist destinations decreased. This also reflects the fragility of the tourism industry to a certain extent. Second, in 2018, Longsheng County implemented the tourism development policy of "ecology, tourism, and poverty alleviation". The development of ethnic and folk culture tourism in Longji Town was supported by policies, and the development level of industries such as scenic inn construction was improved. At the same time, the per capita net income of urban households has increased significantly, the economic and social development of small towns has improved significantly, and the support for the development of the tourism industry has continued to increase. It is noteworthy that in the tourism industry system, Longij's domestic tourism-related indicators perform significantly better than international tourism, indicating that its domestic tourism development level is more prominent than international tourism and its market potential is greater. In contrast, international tourism has been relatively mature after years of rapid development, and it is urgent to change the development mode to increase its contribution to the development of the tourism industry. With the development of the tourism industry and the impact of foreign culture on the local culture of Longji Town, the tourism development of Longji Town must face the problem of assimilation of ethnic folk culture by foreign culture.

From the perspective of the construction system of ethnic tourist towns, the comprehensive evaluation function value of Longji Town's construction showed a fluctuating upward trend under the comprehensive influence of multiple factors from 2013 to 2018. The comprehensive evaluation function value increased from 0.350 in 2013 to 0.736 in 2018 . From 2013 to 2018, the index values of economic and social factors of Longji continued to increase, and the index values of resources and environment declined to a certain extent. It shows that the overall level of township construction is on the rise, and the support for the development of the tourism industry is constantly increasing. During the construction of Longji Town, although tourism development can promote the improvement of the level of small-town construction, the decline in the level of social, economic, resource, and environmental development restricts the improvement of the overall development level of small towns.

\subsection{Analysis of Coupling Degree and Coupling Coordination Degree between the Construction of Ethnic Tourist Towns and the Integration and Development of Tourism Industry}

It can be seen from Figure 1 and Table 3 that the coupling degree from 2013 to 2018 is between 0.872 and 0.999 . According to the annual change rate of the coupling degree, the coupling degree between the construction of Longi Town and the tourism industry is at a high score and fluctuating development trend. At the same time, the development between the two interacts and influences. This period can be divided into three stages according to the annual rate of change in coupling degree. The period from 2013 to 2015 is the stable development stage of the coupling degree, the function value is between 0.999 
and 0.975 , and the annual change rate of the coupling degree is low. The period from 2016 to 2017 is the development stage of the decline of coupling degree, and the function value is between 0.923 and 0.872 , which are all lower than the development level of the same period. The year 2018 is the stage of development of the rebound of the coupling degree, with the function value reaching 0.999. Compared with the previous year, the annual rate of change reached 0.127 .

At the same time, the value of the coupling coordination degree fluctuates between 0.533 and 0.859 , showing an upward trend of fluctuations in general. From 2013 to 2014, it was in the stage of barely coordinated development. From 2015 to 2017, it was in the primary stage of coordinated development. In 2018, it reached the stage of good coordinated development. The years 2015 and 2017 are the demarcation points of system coupling and coordination degree, which reflects the different degree of coordinated development between $\mathrm{F}(\mathrm{x})$ and $\mathrm{G}(\mathrm{y})$. Before 2015, the coordinated development effect of town construction and tourism was not strong, and the mutual promotion effect was relatively weak. After 2015, the social security system and the primary and secondary industries for the construction of small towns were still growing steadily, and the degree of system coupling and coordination changed from the barely coupling coordination to the primary coupling coordination. In 2018, the government increased its investment in the tourism development of Longji Town, and the tourism industry economy was improved, prompting the coupling and coordination of the construction of small towns and the tourism industry system to reach a stage of good coupling and coordinated development.

According to the relationship between $F(x)$ and $G(x)$, each coupling coordination degree can be divided into tourism industry development lagging type $(F(x)>G(y))$, ethnic tourism small-town development lagging type $(\mathrm{F}(\mathrm{x})<\mathrm{G}(\mathrm{y}))$ and the construction of ethnic tourism towns and the simultaneous development of tourism industry $(F(x)=G(y))$. From Figure 1 and Table 3, we can see that 2013, 2014, 2015, and 2018 belong to the lagging development of ethnic tourism towns, 2016 and 2017 are tourism development lagging types. It shows that the construction and development of Longji Town cannot meet the needs of the development of the tourism industry. The rapid development of tourism requires Longji Town to protect national folk culture, improve the social security system, and improve the economic and industrial structure. On the other hand, according to the development requirements of Longji Town as an "international tourist town", the leading role of the tourism industry in the construction of small towns fluctuates greatly, and the role is lack of stability. For example, the development level of the tourism industry continued to lag behind the development level of Longji Town in 2016 and 2017.

\section{Conclusions and Discussion}

\subsection{Conclusions}

Based on the analysis of the mechanism of the coordinated development of the construction of ethnic minority characteristic tourist towns and the tourism industry, this article constructed a coupling index system between the two and introduced coupling evaluation models and calculation methods. Taking Longji Town as the research object, we conducted an empirical study on the coupling and coordination relationship between the two in Longji Town from 2013 to 2018. The study found:

(1) Based on the analysis of the relationship and mechanism between the construction of ethnic minority tourism towns and the tourism industry, this article believed that there are coupling development characteristics between the two systems, and the elements of the systems interact and influence each other. Through the organization and evolution of the internal elements of the system, the two are coordinated with each other.

(2) The comprehensive development index of Longji Township is showing a steady upward development trend in general, and the comprehensive development index of the tourism industry shows a fluctuating and rising development trend. It shows that the construction level of Longii Town and the development of the tourism industry have 
increased significantly in recent years, and stakeholders in Longi Town use different methods to try to promote the town's construction and development.

(3) The degree of coupling and coordination between the construction of Longji Town and the tourism industry has increased from barely coordinated coupling to good coordination, indicating that the mutual promotion between the two systems is becoming stronger and the trend of coordinated development is becoming more and more obvious. The degree of coupling and coordination between the construction of Longji Town and the tourism industry is shown: the lagging development of the construction level of ethnic tourist towns and the lagging development of the tourism industry appear alternately. The guiding role of the development of the tourism industry in the construction of small towns fluctuates greatly, and there is a lack of stability.

\subsection{Discussion}

According to the above analysis, the characteristics of the ethnic tourism system that meet the development requirements of the construction of minority characteristic tourist towns are an important driving force to promote the realization of the sustainable development goals of minority characteristic tourist towns. Therefore, using ethnic tourism to guide the construction of minority characteristic tourist towns and the coordinated development of tourism industry is an effective path choice for the sustainable development of ethnic characteristic tourist towns. The mechanism and evolution of the coupling system of the construction of minority characteristic tourist towns and the development of tourism industry provide an important reference for the realization of this goal. According to the top-down deduction direction, the sustainable development path of minority characteristic tourist towns can be expressed as: goal-response policy coordination. The goal of the route is the sustainable development of minority characteristic tourist towns. The main body of the system responds to the target pressure, to drive the target, choose the development path, and formulate the policy. The government is the main respondent in the whole process. The policy effect is the most important driving force and guarantees to promote the coordinated development of the construction of minority characteristic tourist towns and the development of tourism industry. The design of the policy system should be based on the evolutionary law and coordination mechanism of the small-town constructiontourism industry development system and adopt a combination of macro-control and market regulation to guide the coordinated development of the system. Specifically, in the initial stage of coupling, the government can set the direction for future development and provide relevant policy support for the development of ethnic tourism [58]. The initial stage of tourism development investment is relatively large, but the relative benefit is not high. Meanwhile, the residents' enthusiasm for participation is not high. So, government investment, guidance, promotion, and management are needed to promote the construction of minority characteristic tourist towns and the development of the tourism industry. In the subsequent adjustment stage, tourism benefits gradually became clear and enterprises and residents' awareness of participation increased, but contradictions and conflicts broke out in the development of tourist towns. In order to realize the healthy and orderly development of the coupling system of small-town construction and tourism industry development, relevant policies, regulations, and systems need to be regulated, guided, supported, and promoted [59-61]. The rapid coupling of industrial development improves the tourism competitiveness of small towns [62], thereby driving the coordinated development of society, economy, resources, and environment in small towns.

In recent years, many scholars have conducted research on the coordinated development relationship between towns and tourism $[17,32,33]$ and recognized that the coordinated development of urban construction and tourism is an effective way for sustainable urban development, providing a theoretical basis for the development of this article. However, these research scales do not include small-scale towns, such as tourist towns, nor discuss the influence of the authenticity of local culture on the development level of 
tourist destinations. This work attempts to enrich the content of urban construction and tourism research.

In the quantitative study of the coupling degree between the construction of minority characteristic tourist towns and the tourism industry development system, the construction of the evaluation index system of each subsystem is its foundation. Relatively speaking, the evaluation index system for the tourism industry development is more mature than the evaluation index system for the construction of minority characteristic tourist towns. Although a lot of research has been done on the evaluation index system for the construction of minority characteristic tourist towns, it is limited by the principle of reality and lack of reference research, and its index system needs to be further tested and improved. Constructing a complete and scientific evaluation index system for the construction of minority characteristic tourist towns is a process of continuous research and exploration. Combining field surveys should be an effective means to construct an evaluation index system for the construction of minority characteristic tourist towns. Longji Town is a typical case of coupling research on small-town construction and tourism industry development, but a single case study has limitations. Further research can consider the construction of different types of tourist towns and the coupling mechanism of tourism industry development and provide a more scientific policy reference for formulating sustainable development paths for small tourist towns in accordance with local conditions.

Longji Town is a typical case of coupling research on small-town construction and tourism industry development, but a single case study has limitations. Different types and different development stages of ethnic minority characteristic tourist towns have different development characteristics. Discussing the characteristics of their systematic coupling and coordinated development will help reveal the law of coordinated development of ethnic characteristic tourist towns. At the same time, the coordinated development status of ethnic minority characteristic tourist towns is not static. Using logistic models and other methods to predict its development status can provide more scientific guidance for the formulation of sustainable development strategies for minority characteristic tourist towns. Therefore, this is the direction of our further research.

Author Contributions: Conceptualization, L.L.; methodology, L.L.; formal analysis, L.L.; writingoriginal draft preparation, L.L.; writing-review and editing, L.L. and J.L.; supervision, J.L. All authors have read and agreed to the published version of the manuscript.

Funding: This research received no external funding.

Institutional Review Board Statement: Not applicable.

Informed Consent Statement: Not applicable.

Data Availability Statement: The objective data of this article came from the officially published "Longsheng Statistical Yearbook" and can be found in the following link, http:/ / www.glls.gov.cn/ zjls/lsnj/.

Conflicts of Interest: The authors declare no conflict of interest.

\section{References}

1. Mullins, P. Tourism Urbanization. Int. J. Urban Reg. Res. 1991, 15, 326-342. [CrossRef]

2. Sharpley, R. Tourism, sustainable development and the theoretical divide: 20 years on. J. Sustain. Tour. 2020, 28, 1932-1946. [CrossRef]

3. Haralambopoulos, N.; Pizam, A. Perceived impacts of tourism-The case of Samos. Ann. Tour. Res. 1996, 23, 503-526. [CrossRef]

4. Qian, J.; Feng, D.; Zhu, H. Tourism-driven urbanization in China's small town development: A case study of Zhapo Town, 1986-2003. Habitat Int. 2012, 36, 152-160. [CrossRef]

5. Li, B. A summary research of the external and internal town tourism. Tour. Trib. 2010, 25, 88-95.

6. Yang, L.; Liu, P.; Li, Q.; Deng, Y.; Li, B. The maturation and its evaluation system of tourism town: A case study of hunan customs and cultural tourism town. Econ. Geogr. 2017, 37, 191-197.

7. McGehee, N.G.; Andereck, K.L. Factors predicting rural residents' support of tourism. J. Travel Res. 2016, 43, 131-140. [CrossRef]

8. Davis, J.S.; Morais, D.B. Factions and enclaves: Small towns and socially unsustainable tourism development. J. Travel Res. 2016, 43, 3-10. [CrossRef] 
9. Mbaiwa, J.E. Enclave tourism and its socio-economic impacts in the Okavango Delta, Botswana. Tour. Manag. 2005, 26, 157-172. [CrossRef]

10. Yang, C.Y.; Huang, J.; Lin, Z.B.; Zhang, D.X.; Zhu, Y.; Xu, X.H.; Chen, M. Evaluating the symbiosis status of tourist towns: The case of Guizhou Province, China. Ann. Tour. Res. 2018, 72, 109-125. [CrossRef]

11. Tao, T.C.H.; Wall, G. Tourism as a sustainable livelihood strategy. Tour. Manag. 2009, 30, 90-98. [CrossRef]

12. Tang, H.; Liu, Y.; Ma, X. Effect evaluation of coordinated development between tourism industry and new urbanization-A case study of Zhangjiajie. Econ. Geogr. 2017, 37, 216-223.

13. Lu, L.; Ge, J.-B. Reflection on the research progress of tourism urbanization. Geogr. Res. 2006, 25, 741-750.

14. Zhang, H.Q.Q.; Luo, J.M.; Xiao, Q.; Guillet, B.D. The impact of urbanization on hotel development: Evidence from Guangdong Province in China. Int. J. Hosp. Manag. 2013, 34, 92-98. [CrossRef]

15. Grah, B.; Dimovski, V.; Peterlin, J. Managing sustainable urban tourism development: The case of Ljubljana. Sustainability 2020, 12, 792. [CrossRef]

16. Xi, J.C.; Wang, X.G.; Kong, Q.Q.; Zhang, N. Spatial morphology evolution of rural settlements induced by tourism A comparative study of three villages in Yesanpo tourism area, China. J. Geogr. Sci. 2015, 25, 497-511. [CrossRef]

17. Lai, Z.Z.; Ge, D.M.; Xia, H.B.; Yue, Y.L.; Wang, Z. Coupling coordination between environment, economy and tourism: A case study of China. PLoS ONE 2020, 15, e228426. [CrossRef] [PubMed]

18. Gao, N.; Ma, Y.; Li, T.; Bai, K. Study on the coordinative development between tourism industry and urbanization based on coupling model: A case study of Xi'an. Tour. Trib. 2013, 28, 62-68.

19. Wang, Z.; Yu, H. Study on coupling development between development of tourism industry and small town construction in Zhangjiajie city. Econ. Geogr. 2012, 32, 165-171.

20. MacCannell, D. Staged authenticity: Arrangements of social space in tourist settings. Am. J. Sociol. 1973, 79, 589-603. [CrossRef]

21. Gao, Y.; Lin, C. Tourists' authentic perception and satisfaction of the black-clothed Zhuang national culture. Tour. Trib. 2007, 22, 78-84.

22. Nasser, N. Planning for urban heritage places: Reconciling conservation, tourism, and sustainable development. J. Plan. Lit. 2003, 17, 467-479. [CrossRef]

23. Hsieh, W.H.; Ou, H.-J. Planning for sustainable development of tourism in Songkou ancient town. MATEC Web Conf. 2017, 119, 1035.

24. Badar, R.N.; Bahadure, S.P. Assessing tourism sustainability in hill towns: Case study of Shimla, India. J. Mt. Sci. 2020, 17, 2241-2261. [CrossRef]

25. Garcia-Hernandez, M.; de la Calle-Vaquero, M.; Yubero, C. Cultural heritage and urban tourism: Historic city centres under pressure. Sustainability 2017, 9, 1346. [CrossRef]

26. Muler Gonzalez, V.; Coromina, L.; Galí, N. Overtourism: Residents' perceptions of tourism impact as an indicator of resident social carrying capacity-Case study of a Spanish heritage town. Tour. Rev. 2018, 73, 277-296. [CrossRef]

27. Tang, $X$. The social and cultural impact of ancient village tourism: The relationship between residents' perception, attitude and behavior-A case study of Pingan village in Longji, Guangxi. Hum. Geogr. 2015, 1, 135-142.

28. Liu, Y.; Li, R.; Song, X. Analysis of coupling degree of urbanization and ecological environment in China. J. Nat. Res. 2005, 20, 105-112.

29. Wu, Y.; Zhang, Y.; Wang, Q. Study on the coordination between environment system and economic system. Environ. Pollut. Control 1997, 19, 20-23.

30. Okumus, F.; van Niekerk, M.; Koseoglu, M.A.; Bilgihan, A. Interdisciplinary research in tourism. Tour. Manag. 2018, 69, 540-549. [CrossRef]

31. Seongseop Kim, S.; McKercher, B. The collective effect of national culture and tourist culture on tourist behavior. J. Travel Tour. Mark. 2011, 28, 145-164. [CrossRef]

32. Liu, J.; Li, C.; Tao, J.; Ma, Y.; Wen, X. Spatiotemporal coupling factors and mode of tourism industry, urbanization and ecological environment: A case study of Shaanxi, China. Sustainability 2019, 11, 4923. [CrossRef]

33. Zhang, T.; Li, L. Research on temporal and spatial variations in the degree of coupling coordination of tourism-urbanizationecological environment: A case study of Heilongjiang, China. Environ. Dev. Sustain. 2020. [CrossRef]

34. Sun, Q.; Zhang, X.; Zhang, H.; Niu, H. Coordinated development of a coupled social economy and resource environment system: A case study in Henan Province, China. Environ. Dev. Sustain. 2017, 20, 1385-1404. [CrossRef]

35. Scheyvens, R. Linking tourism to the sustainable development goals: A geographical perspective. Tour. Geogr. 2018, 20, 341-342. [CrossRef]

36. Brahmasrene, T.; Lee, J.W. Assessing the dynamic impact of tourism, industrialization, urbanization, and globalization on growth and environment in Southeast Asia. Int. J. Sustain. Dev. World Ecol. 2016, 24, 362-371. [CrossRef]

37. Luo, J.M.; Qiu, H.; Lam, C.F. Urbanization impacts on regional tourism development: A case study in China. Curr. Issues Tour. 2015, 19, 282-295. [CrossRef]

38. Fang, L. Empirical research on the impact of urbanization on regional tourism economy in china basing on panel data. In Proceedings of the 2018 9th International Conference on E-business, Management and Economics-ICEME, Waterloo, ON, Canada, 2-4 August 2018; pp. 101-105. 
39. Maruyama, N.; Woosnam, K.M. Residents' ethnic attitudes and support for ethnic neighborhood tourism: The case of a Brazilian town in Japan. Tour. Manag. 2015, 50, 225-237. [CrossRef]

40. Luo, J.M.; Qiu, H.; Goh, C.; Wang, D. An analysis of tourism development in China from urbanization perspective. J. Qual. Assur. Hosp. Tour. 2015, 17, 24-44. [CrossRef]

41. Maruyama, N.U.; Keith, S.J.; Woosnam, K.M. Incorporating emotion into social exchange: Considering distinct resident groups attitudes towards ethnic neighborhood tourism in Osaka, Japan. J. Sustain. Tour. 2019, 27, 1125-1141. [CrossRef]

42. Wang, S.-L.; Li, Y.-C.; Zhang, C.-P. Analysis of the effect of social support on sustainable competitive advantage in tourism industry-Based on the perspective of living-ecology-production integrated space. Rev. Cercet. Interv. Soc. 2020, 71, $250-263$.

43. Rasoolimanesh, S.M.; Roldán, J.L.; Jaafar, M.; Ramayah, T. Factors influencing residents' perceptions toward tourism development: Differences across rural and urban world heritage sites. J. Travel Res. 2016, 56, 760-775. [CrossRef]

44. Jaafar, M.; Noor, S.M.; Rasoolimanesh, S.M. Perception of young local residents toward sustainable conservation programmes: A case study of the Lenggong World Cultural Heritage Site. Tour. Manag. 2015, 48, 154-163. [CrossRef]

45. Andereck, K.L.; Valentine, K.M.; Vogt, C.A.; Knopf, R.C. A Cross-cultural analysis of tourism and quality of life perceptions. J. Sustain. Tour. 2007, 15, 483-502. [CrossRef]

46. Liang, Z.-X.; Hui, T.-K. Residents' quality of life and attitudes toward tourism development in China. Tour. Manag. 2016, 57, 56-67. [CrossRef]

47. Woosnam, K.M.; Maruyama, N.U.; Ribeiro, M.A.; Joo, D. Explaining minority residents' attitudes of ethnic enclave tourism from general perceptions of tourism impacts. J. Tour. Cult. Chang. 2019, 17, 467-484. [CrossRef]

48. Royo-Vela, M. Rural-cultural excursion conceptualization: A local tourism marketing management model based on tourist destination image measurement. Tour. Manag. 2009, 30, 419-428. [CrossRef]

49. Lin, L.-F.; Huang, G.-h.; Wang, Y. Research on the evaluation system of the authenticity of ethnic cultural tourism products based on factor analysis. Hum. Geogr. 2010, 25, 39-43.

50. Katahenggam, N. Tourist perceptions and preferences of authenticity in heritage tourism: Visual comparative study of George Town and Singapore. J. Tour. Cult. Chang. 2020, 18, 371-385. [CrossRef]

51. LI, Z. Research on the coupling mechanism and coordinated development of rural revitalization-Rural tourism system: A case study on Fenghuang County in Hunan. Geogr. Res. 2019, 38, 643-654.

52. Paunovic, I.; Jovanovic, V. Implementation of sustainable tourism in the German Alps: A case study. Sustainability 2017, 9, 226. [CrossRef]

53. Liu, A.; Yang, C.; Ming, Q.; Zhang, H.; Lu, B. Spatial-temporal coordination and driving forces of provincial culture industry and tourism industry in China. Econ. Geogr. 2020, 40, 203-212.

54. Hou, B.; Zhou, X.-Q. Assessment and evaluation of integration of the culture industry and tourism industry in Yangtze River Delta. Econ. Geogr. 2015, 35, 211-217.

55. Li, Y.; Li, Y.; Zhou, Y.; Shi, Y.; Zhu, X. Investigation of a coupling model of coordination between urbanization and the environment. J. Environ. Manag. 2012, 98, 127-133. [CrossRef] [PubMed]

56. Cong, X. Expression and mathematical property of coupling model, and its misuse in geographical science. Econ. Geogr. 2019, 39, $18-25$.

57. Chongbin, L. Quantitative judgement and classification system for coordinated development of environment AMD economy. Trop. Geogr. 1999, 19, 171-176.

58. Logar, I. Sustainable tourism management in Crikvenica, Croatia: An assessment of policy instruments. Tour. Manag. 2010, 31, 125-135. [CrossRef]

59. Kensbock, S.; Jennings, G. Pursuing: A grounded theory of tourism entrepreneurs' understanding and praxis of sustainable tourism. Asia Pac. J. Tour. Res. 2011, 16, 489-504. [CrossRef]

60. Hwang, D.; Stewart, W.P.; Ko, D.-W. Community behavior and sustainable rural tourism development. J. Travel Res. 2011, 51, 328-341. [CrossRef]

61. Korca, P. Resident perceptions of tourism in a resort town. Leis. Sci. 1998, 20, 193-212. [CrossRef]

62. Sanz-Ibanez, C.; Clave, S.A. The evolution of destinations: Towards an evolutionary and relational economic geography approach. Tour. Geogr. 2014, 16, 563-579. [CrossRef] 